EDITORIAL

\title{
La batalla por una mejor salud de los pueblos
}

\author{
Fighting for better health of the peoples
}

Preservar es cuidar. Para preservar la palabra clave es prevenir.

Consumimos más recursos naturales de los que la naturaleza puede restituir. Los desechos que la actividad humana produce rebasan la capacidad de la naturaleza para procesarlos. Estos hechos vienen ocurriendo desde décadas pasadas, sus consecuencias son variadas y todas graves: crisis energéticas, sequías e inundaciones, incendios forestales, desertificación, contaminación, reducción de la biodiversidad, mayor intensidad y frecuencia de tormentas tropicales y otros efectos tanto o más negativos.

Las afectaciones sobre la salud humana de estos fenómenos naturales generados al impulso de conductas humanas desafortunadas, son notables.

Para el 2010 se estiman en 1000 millones de personas las que no tienen acceso a aguas limpias (ya no se habla de potable). Y 2500 millones no cuentan con saneamiento local satisfactorio. La Organización para la Agricultura y la Alimentación informa de 1020 millones de hambrientos en el mundo. Los sueños de las metas del milenio no se alcanzarán.

Si intentamos llegar a "la causa de las causas", el eslabón inicial lo encontraremos en la formación económica social que privilegia la obtención de ganancias monetarias por encima de cualquier otra consideración. El dinero obtenido en el mercado, es la razón de ser de la economía. De ahí es que llegamos al consumo desmedido de combustibles fósiles, no renovables, la contaminación extendida con gases de efecto invernadero, el cambio climático, la deforestación galopante, las guerras de rapiña.

¿Será prevenible todo esto? Sí, es prevenible en términos técnicos y económicos. Puede controlarse, pero solo es posible a partir de la voluntad política de los gobiernos y clases dirigentes, que están en manos de voraces capitalistas neoliberales, dominados por un imperio que desconoce acuerdos como el de Kyoto, que ahoga económicamente las débiles economías de los países llamados pobres, que hace de las guerras un negocio altamente rentable. 
Todas las nefatas situaciones mencionadas y otras muchas son nocivas a la salud, causan enfermedades, invalidez y muerte. Por esto la promoción y prevención deben ir más allá de la lucha por las aguas limpias y el saneamiento, más allá de los programas de vacunación, más allá de la búsqueda temprana de las enfermedades (preclínica), más allá de educar para alimentarnos mejor. Las batallas deberán dirigirse a controlar las emanaciones de $\mathrm{CO}_{2}$, proteger los bosques y selvas, reconocer el derecho al agua como derecho humano, asegurar para todos, el acceso a una alimentación sana y a servicios de salud. Esto solo se ganará en el terreno de las luchas sociales y políticas para rescatar las conquistas que se han perdido desde finales del pasado siglo y avanzar mucho más.

Hoy en América Latina esto se vislumbra. La Revolución Cubana llegó a su 50 aniversario con grandes avances en la dirección que proponemos. La Revolución Bolivariana ya muestra logros notables. El Movimiento al Socialismo en Bolivia, llevó al poder a un hombre de los pueblos originarios. La Revolución Ciudadana preserva el territorio de los pueblos autóctonos de la voracidad de los consorcios petroleros.

Fidel Castro libra una épica batalla por la paz, ya se le sigue por movimientos importantes y rompe la barrera de medios de comunicación en manos del neoliberalismo.

Para cada uno de los que hacemos salud pública, en Cuba o en cualquier parte del mundo el momento es de lucha. Primero de denuncia, luego de concertación (todos juntos) hacia las metas más inmediatas, después hacia unas nuevas metas del milenio. Sin la pobreza de las que se anunciaron en el 2000, y en manos de voluntades políticas firmes, decididas, necesariamente revolucionarias.

Francisco Rojas Ochoa Profesor 